\title{
General practice care and patients' priorities in Europe: an international comparison
}

\author{
Michel Wensing ${ }^{\mathrm{a}, *}$, Jan Mainz ${ }^{\mathrm{b}}$, Pedro Ferreira ${ }^{\mathrm{c}}$, \\ Hilary Hearnshaw ${ }^{\mathrm{d}}$, Per Hjortdahl e, Frede Olesen ${ }^{\mathrm{b}}$, Shmuel Reis ${ }^{\mathrm{f}}$, \\ Mats Ribacke ${ }^{\mathrm{g}}$, Joachim Szécsényi ${ }^{\mathrm{h}}$, Richard Grol ${ }^{\mathrm{a}}$ \\ a Centre for Quality of Care Research, Universities of Nijmegen and Maastricht, P.O. Box 9101, \\ $6500 \mathrm{HB}$, Nijmegen, The Netherlands \\ ${ }^{\mathrm{b}}$ Research Unit for General Practice, Aarhus University, Aarhus, Denmark \\ ${ }^{\mathrm{c}}$ Centre for Social Studies, University of Coimbra, Coimbra, Portugal \\ ${ }^{\mathrm{d}}$ Eli Lilly National Clinical Audit Centre, University of Leicester, Leicester, UK \\ e Department of Family Medicine, University of Oslo, Oslo, Norway \\ ${ }^{\mathrm{f}}$ Department of Family Health Care, The Technion, Haifa, Israel \\ g Department of Family Medicine, University of Uppsala, Uppsala, Sweden \\ ${ }^{\mathrm{h}}$ Institute on Applied Quality Improvement and Research in Health Care, Göttingen, Germany
}

Accepted 27 July 1998

\begin{abstract}
Insight into patients' priorities with respect to health care should complement the views of professionals and policy makers on what is thought to be appropriate health care. To determine the strengths and weaknesses of general practice care from patients' perspectives written surveys were performed among patients in Denmark, Germany, Israel, Netherlands, Norway, Portugal, Sweden and United Kingdom $(n=3540)$. The potential quality problems identified were spread over the different countries: the low involvement of general practitioners in out-of-hours services in Portugal; the low provision of routine screening in Sweden, Norway and The Netherlands; the lack of a defined patient population in Germany; the lack of a formal gatekeeper role to secondary care in general practice in Germany and Sweden; and the low number of home visits in Sweden. (C) 1998 Elsevier Science Ireland Ltd. All rights reserved.
\end{abstract}

* Corresponding author. Tel.: + $31 \quad 24$ 3615305; fax: + $31 \quad 24$ 361540166; e-mail: m.wensing@hsv.kun.nl

0168-8510/98/\$ - see front matter (C) 1998 Elsevier Science Ireland Ltd. All rights reserved.

PII S0168-8510(98)00040-2 
Keywords: General practice; Patient satisfaction; Patient centredness; International comparison

\section{Introduction}

The provision of primary care is a crucial aspect of a health care system [1]. The organization of primary care varies across different countries, for instance with respect to the gatekeeper role of the general practitioner to secondary care [2] and the range of services provided in general practice [3]. There is an ongoing debate on what constitutes good primary care [4], for instance with respect to the claims that the gatekeeper role of the primary care physician results in better health outcomes [5].

It is important to consider patients' needs and preferences in the discussion on primary care. Insight into patients' priorities with respect to health care should complement the views of professionals and policy makers on what is appropriate health care. Patients' evaluations of health care provision have shown to vary across different countries [6-9]. They may be related to specific features of the health care system [2,9]. For instance, a comparison of ten western countries suggested that a strong primary care system was positively related to high satisfaction of patients with health care, if the influence of expenses on health care was controlled [9]. The exception was the United Kingdom, which has a strong primary care system and relatively low expenditure, but where patients were less satisfied with the care provided than in other countries.

Insight into the international variations of patients' priorities with respect to general practice may help policy makers to assess the quality of general practice in their country, at least from patients' perspectives (Table 1). The absence of a specific aspect of general practice care in a country may be a quality problem, if this aspect is highly prioritized by patients. On the other hand, an aspect of care which is absent in a country and not prioritized by patients can probably receive less

Table 1

Conceptual framework

Patients' priorities related to Aspect of general practice care

this aspect

Absent Present

High priority

Low priority
Potential quality problem Aspect which should receive less attention
Aspect which should be maintained Aspect which is taken for granted and should be maintained or aspect which is less important and should be ignored 
attention. Aspects which are present in a country and also highly prioritized by patients should probably be maintained. Aspects which are present, but not highly prioritized by patients may receive less attention or may be taken for granted by patients.

This study explores to what extent patients' priorities with respect to general practice care vary across countries with different types of general practice care in Europe, using empirical data from international surveys among patients.

\section{Methods}

\subsection{Subjects and data-collection}

Surveys were performed in seven European countries (Denmark, Germany, Netherlands, Norway, Portugal, Sweden, United Kingdom) and Israel. The study population consisted of patients with recent experience with general practice care. A sample of patients who visited the general practitioner (GP) from at least 12 practices per country was approached. The practices were stratified according to the geographic area (four practices in rural areas, four in towns and four in larger cities) and the practice size (four were low staffed, four medium staffed and four high staffed-except Germany, where only low and medium staffed practice exist). Each GP sampled at least 60 patients using the following inclusion criteria: 18 years or older, being able to understand the native language. The survey was anonymous, so reminders were not sent (except for Denmark, where a special reminding procedure was used). Practices with a response rate below $15 \%$ were excluded from the study ( $n=22$ patients in total), because they probably did not hand out all questionnaires. Patients could fill in the questionnaire at home and use a stamped and addressed envelope to send it tot the research centre for analysis.

\subsection{Instruments}

A questionnaire of 40 items was developed, focusing on what was expected to be important to patients and covering all important aspects of general practice care: technical and interpersonal care, outcomes and organization of care [10]. A five-point answering scale was used, running from 'not at all important' to 'extremely important'. Two questions were translated inconsistently in different countries so they were left out of the analyses. The questionnaire also contained questions on patients' age, sex and number of recent visits to the GP.

In order to describe general practice care in the eight countries factual data from two other studies were used: involvement in out-of-hours services [3], provision of routine screening [3], care for a defined patient population [2], formal gatekeeper role to secondary care [3] and home visits to patients [11] (Table 2). These aspects were chosen because they related closely to specific items on patients' priorities. 


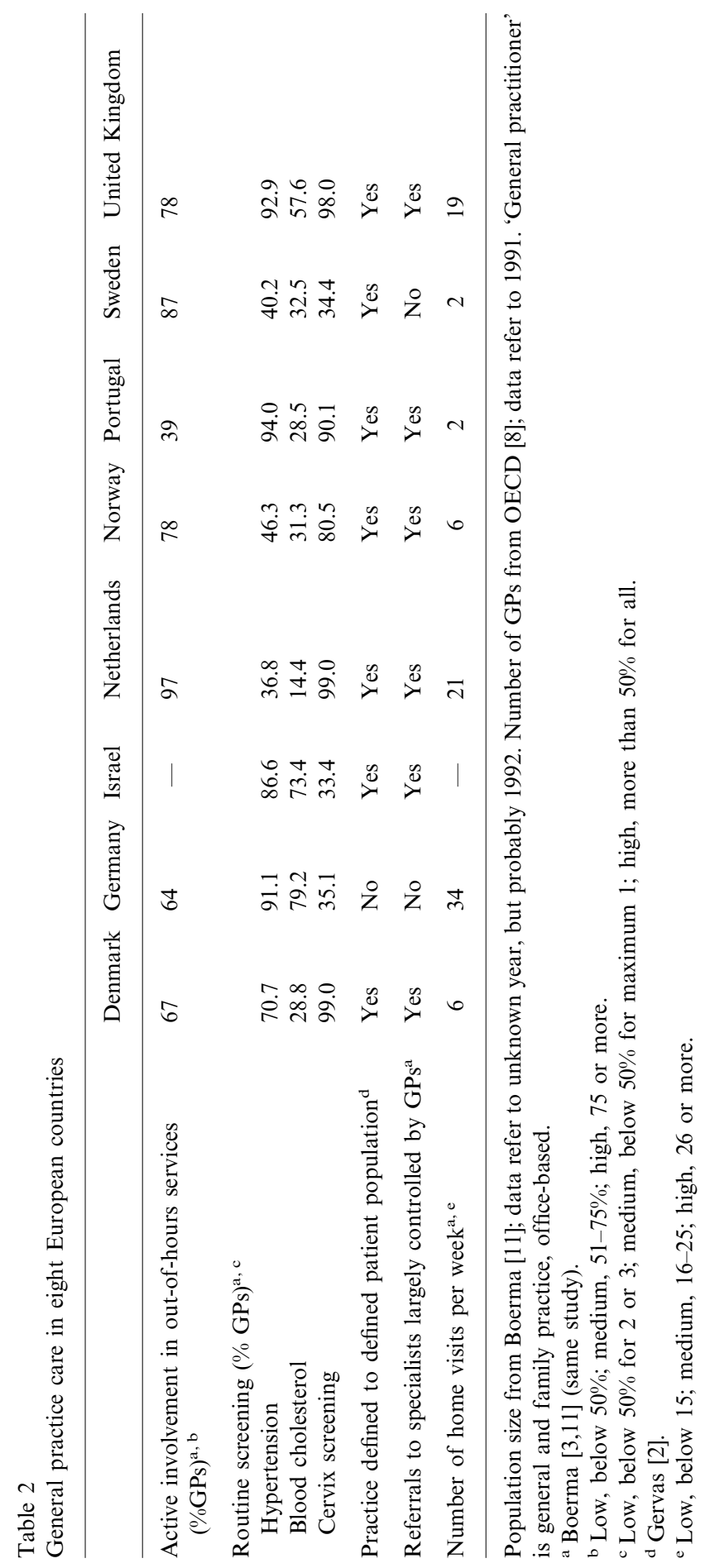




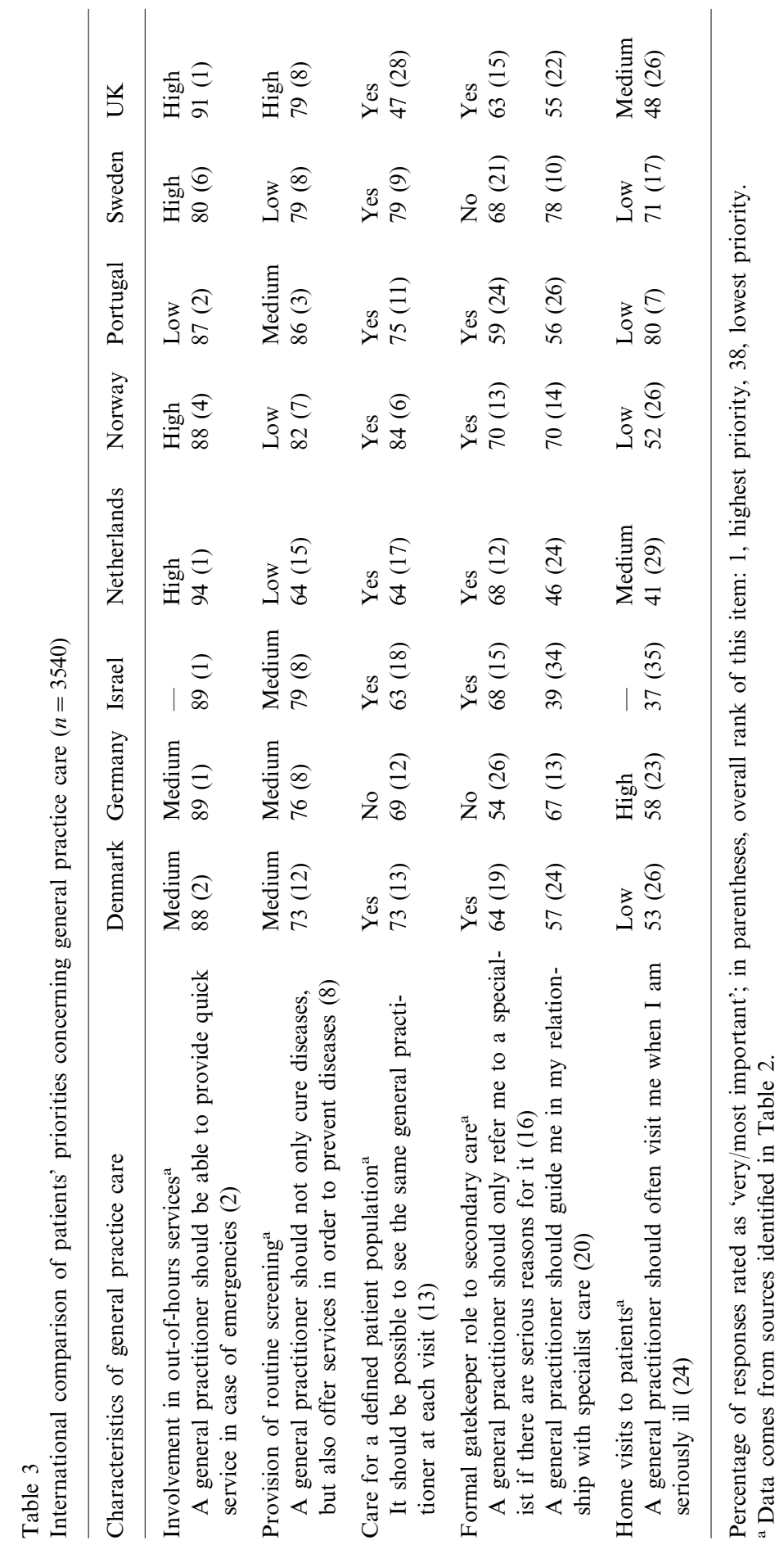




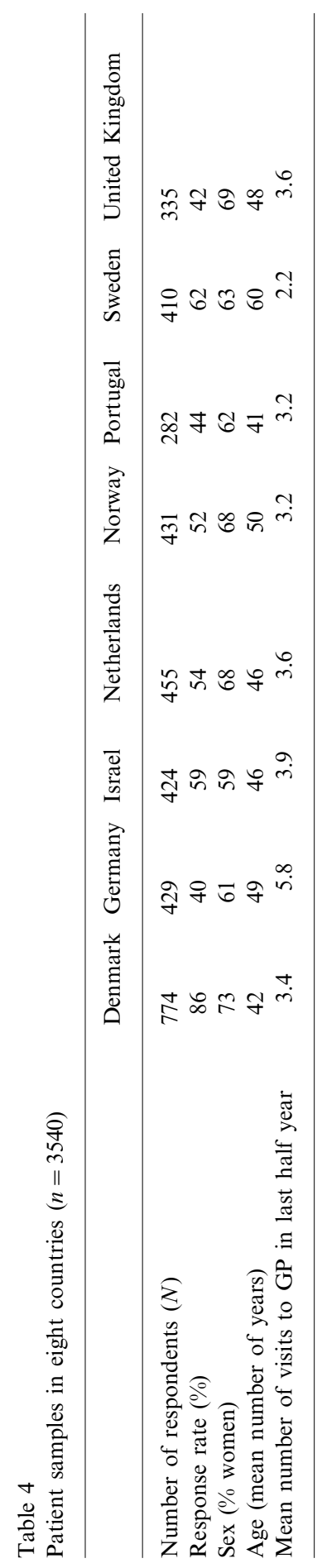


Table 5

A general practitioner should be able to provide quick service in case of emergencies (overall rank, 2)

Patients' priorities related to Involvement in out-of-hours services (percentage of GPs who report this aspect active involvement)

\begin{tabular}{ll}
\hline Low $(<50 \%)$ & $\begin{array}{l}\text { Medium }(51- \\
75 \%)\end{array} \quad$ High $(>75 \%)$
\end{tabular}

\begin{tabular}{llll}
\hline High priority (ranked 1-10) & Portugal & $\begin{array}{l}\text { Denmark, Ger- } \\
\text { many }\end{array}$ & $\begin{array}{l}\text { Netherlands, Norway, Sweden, } \\
\text { United Kingdom }\end{array}$ \\
$\begin{array}{l}\text { Medium priority (ranked 11- } \\
\text { 20) }\end{array}$ & - & - \\
Low priority (ranked 21-38) & - & - & -
\end{tabular}

Data for Israel were not available.

\subsection{Analysis}

For the description of patients' priorities the percentage of patients that answered 'very important' or 'extremely important' for a particular aspect of care was used. Using these percentages an importance rank order of items for each country was calculated, ranging from 1 (highest priority) to 38 (lowest priority). For this study these rank numbers were categorized into 'high' (rank 1-10), 'medium' (rank 11-20) and 'low' (rank 21-38) (Table 3).

\section{Results}

The sample included 3540 patients (response rate 55\%, country specific range $42-86 \%$ ) (Table 4). In all countries about two thirds of the patients were women. The mean age of the patients was between 40 and 50 years, except in Sweden where the mean age was 60 years. The mean number of visits to the GP in the last half year varied from 2.2 in Sweden to 5.8 in Germany.

Tables 5-10 show the results with respect to the six characteristics of general practice. Patients in all countries prioritized highly that the GP should be able to provide quick services in case of emergencies. GPs' involvement in out-of-hours services was high in the Netherlands, Norway, Sweden and the United Kingdom. On the other hand, it was low in Portugal and medium in Denmark and Germany.

In many countries patients prioritized highly that the GP should offer preventive services. Nevertheless, the United Kingdom was the only country where the level of routinely screening patients was high. In Sweden and Norway, many GPs did not routinely provide preventive screening. This is also the situation in The Netherlands, where patients prioritized prevention at a medium level. In the remaining countries patients' priorities on provision of preventive services were medium or high, but the actual amount of routine screening provided was medium. 
Table 6

A general practitioner should not only cure diseases, but also offer services in order to prevent diseases (overall rank, 8)

Patients' priorities related to Provision of routine screening ${ }^{\mathrm{a}}$ this aspect

\begin{tabular}{lll}
\hline Low ( $>50 \%$ for a maxi- & Medium $(>50 \%$ & High $(>50 \%$ of \\
mum of one indicator) & $\begin{array}{l}\text { for two indica- } \\
\text { tors })\end{array}$ & three indicators)
\end{tabular}

\begin{tabular}{llll}
\hline High priority $(1-10)$ & Sweden, Norway & $\begin{array}{l}\text { Germany, Israel, } \\
\text { Portugal }\end{array}$ & United Kingdom \\
Medium priority $(11-20)$ & Netherlands & Denmark & - \\
Low priority $(21-38)$ & - & - & -
\end{tabular}

a Percentage of GPs who report routine screening for three indicators: hypertension, blood cholesterol and cervical screening.

German GPs did not care for a defined patient population, while patients prioritized the possibility to see the same GP at each visit at a medium level. The possibility to see the same GP at each visit was prioritized highly by patients in Norway and Sweden, where GPs do care for a defined population. Seeing the same GP was prioritized at a medium level by patients in the remaining countries, where the GP cared for a defined patient population.

It was not in none of the countries a high priority that the GP should refer to a specialist only if there are serious reasons for it. This feature was a low priority in Germany and Sweden, where the GP was not a formal gatekeeper to secondary care. Patients in Portugal did not prioritize this referral policy either. In the remaining countries GPs were a formal gatekeeper to secondary care and GPs' referral policy was fairly important to patients.

Guidance about specialist care from a GP was prioritized highly in Sweden, where GPs were not a formal gatekeeper to secondary care. So this may be quality problem. This guidance was not prioritized highly by patients in Norway, Denmark, Israel, Netherlands, Portugal and United Kingdom. German patients priori-

Table 7

It should be possible to see the same general practitioner at each visit (overall rank, 13)

\begin{tabular}{lll}
\hline $\begin{array}{l}\text { Patients' priorities related to } \\
\text { this aspect }\end{array}$ & Care for a defined patient population \\
\cline { 2 - 3 } & No & Yes \\
\hline $\begin{array}{ll}\text { High priority (1-10) } \\
\text { Medium priority (11-20) }\end{array}$ & - Germany & $\begin{array}{l}\text { Norway, Sweden } \\
\text { Denmark, Israel, Netherlands, Portugal, United } \\
\text { Kingdom }\end{array}$ \\
Low priority (21-38) & - & -
\end{tabular}


Table 8

A general practitioner should only refer me to a specialist if there are serious reasons for it (overall rank, 16)

\begin{tabular}{lll}
\hline $\begin{array}{l}\text { Patients' priorities related to } \\
\text { referral }\end{array}$ & \multicolumn{2}{l}{ Formal gatekeeper to secondary care } \\
\cline { 2 - 3 } & No & Yes \\
\hline $\begin{array}{ll}\text { High priority (1-10) } \\
\text { Medium priority (11-20) }\end{array}$ & - & $\begin{array}{l}\text { Denmark, Israel, Netherlands, Norway, United } \\
\text { Kingdom } \\
\text { Low priority (21-38) }\end{array}$ \\
$\begin{array}{l}\text { Germany, Swe- } \\
\text { den }\end{array}$ & \\
\hline
\end{tabular}

tized the guidance to some extent, but the GP was not a formal gatekeeper to secondary care in Germany.

It was not in any of the countries that patients prioritized frequent visits by the GP in case of serious illness highly. Only patients in Sweden prioritized this feature to some extent. In Denmark and Norway the number of home visits was low, which was consistent with patients' priorities. On the other hand, the number of home visits was high is Germany and medium in the Netherlands and United Kingdom.

\section{Discussion}

This explorative study related patient priorities to specific features of the national systems of general practice care in order to identify quality problems, which aspects of care should be maintained and which aspects may receive less attention. The detailed analysis adds new insights to earlier studies, which showed that patients' views on health care vary across different countries [6-8]. The potential quality problems that were identified were spread over the different countries, in contrast with an earlier study that showed that a stronger primary care system is (almost) consistently related to higher patient satisfaction with care [9].

\section{Table 9}

A general practitioner should guide me in my relationship with specialist care (overall rank, 20)

Patients' priorities related to Formal gatekeeper role to secondary care
this aspect

\begin{tabular}{lll}
\cline { 2 - 3 } & No & Yes \\
\hline High priority (1-10) & Sweden & - \\
Medium priority (11-20) & Germany & Norway \\
Low priority (21-38) & - & $\begin{array}{l}\text { Denmark, Israel, Netherlands, Portugal, United } \\
\text { Kingdom }\end{array}$ \\
\hline
\end{tabular}


Table 10

A general practitioner should often visit me when I am seriously ill (overall rank, 24)

\begin{tabular}{llll}
\hline Patients' priorities related to this aspect & \multicolumn{2}{l}{$\begin{array}{l}\text { Home visits to patients (number of home visits per week } \\
\text { reported by GPs) }\end{array}$} \\
\cline { 2 - 4 } & Low $(<15)$ & Medium $(16-25)$ & High $(>25)$ \\
\hline $\begin{array}{l}\text { High priority }(1-10) \\
\text { Medium priority }(11-20)\end{array}$ & - & - & - \\
Low priority $(21-38)$ & $\begin{array}{l}\text { Sweden } \\
\text { Denmark, Nor- } \\
\text { way }\end{array}$ & $\begin{array}{l}\text { Netherlands, United } \\
\text { Kingdom }\end{array}$ & Germany
\end{tabular}

Data for Israel not available.

Availability in case of emergencies was important for patients in all eight countries, so countries where few general practitioners were involved in out-ofhours services may have a quality problem. This is typically the situation in southern European countries (Italy, Portugal, Spain) [11]. It may also be the situation in specific regions within other countries, such as Denmark and Germany. It is unclear whether patients are satisfied with special agencies for the delivery of out-of-hours services, such as those in Denmark [12], where a doctor who is not the patients' own general practitioner provides the service.

The delivery of preventive services in general practice is prioritized by patients, but delivery varies across the different countries. A low level of routine screening in general practice care, such as is the situation in Norway and Sweden, may be a quality problem from patients' perspectives. It is unclear to what extent the type of preventive services delivered (cervical screening, blood cholesterol screening, blood pressure measurements, etc.) is relevant. Prevention is not always effective, so general practitioners may be reluctant to provide screening and vaccination to large groups of patients. Nevertheless, many patients have high expectations of prevention. For instance, a study in The Netherlands showed that $72 \%$ of the population expects that all diseases can be cured if they are identified at an early stage, while only $18 \%$ of a sample of general practitioners had this belief [13]. So doctors' and patients' perspectives often conflict with respect to prevention.

In countries where the general practitioner does not care for a defined patient population, such as Austria, Belgium, Germany and Switzerland [2], the possibility of seeing the same general practitioner may be a problem. The finding that patients in Norway and Sweden highly prioritized the possibility to see the same GP could be explained by the fact that practices in these countries do not have a formal list system. The overall medium level of priority given to this aspect indicates that weaker types of continuity of care than personal continuity, such as continuity of care within the general practice [14], may be acceptable to patients as well.

Patients did not prioritize highly that the general practitioner only refers them to specialist care if there are serious reasons. Not surprisingly, this was particularly true for Germany and Sweden, where the general practitioner does not have a 
formal gatekeeper role to secondary care. If policy makers decide to introduce the gatekeeper role in these countries, for instance because they expect that it may reduce health care costs, good information for patients is needed to prevent dissatisfaction in patients. Interestingly, the findings were slightly different with respect to the guidance by the general practitioner in the relationship with secondary care. Patients in Sweden prioritized this guidance, so the absence of a formal gatekeeper role for the general practitioner in Sweden may be a quality problem.

The number of home visits made by general practitioners to patients varies considerably, but the priority attached to visits to seriously ill patients was consistently low in all countries. Perhaps German general practitioners should visit their patients less often than they do. However, care is needed, because home visits may be very important for specific patients, such as the chronically ill and the elderly.

A strong aspect of this study is that independent sources of empirical data were used to analyze the relationship between patients' priorities and features of general practice care. A potential problem is variation of general practice care within the countries, which was ignored in this study. For instance, the GP does not have a formal gatekeeper role in Sweden, but in several regions access to secondary care is in fact very difficult without referral from a GP (Dr Mats Ribacke, personal communication). In Norway, practices are not always defined to a specific patient population (Dr Per Hjortdahl, personal communication).

It is difficult to interpret the findings and the causes of the relationships found. Therefore, the focus was on a small number of aspects of care where empirical data were available and where relationships between patient priorities and features of the general practice system could be expected. Furthermore, we focused on implications for health care policy and not on causal factors that determined patient priorities. The number of countries was small, so the generalizability of the findings is unclear, recognizing that most countries in this study have a strong general practice system.

Nevertheless, this study suggests that a detailed analysis can identify relationships between patients' priorities and specific features of general practice care. The international comparison might help health care policy makers to integrate patients' perspectives in their assessment and of national health care systems and in planning changes to the systems. We believe that patients can provide an important contribution to the improvement of the quality of general practice care.

\section{Acknowledgements}

The study was conducted by the European Task Force on Patient Evaluations of General Practice (Europep), with a grant of the European Community (BiomedII).

\section{References}

[1] World Health Organization. Primary health care. Geneva: WHO, 1978.

[2] Gérvas J, Pérez Fernandez M, Starfield BH. Primary care, financing and gatekeeping in western Europe. Fam Pract 1994;11:307-17. 
[3] Boerma WGW, Van der Zee J, Fleming DM. Service profiles of general practitioners in Europe. Br J Gen Pract 1997;47:481-6.

[4] Starfield B. Is primary care essential? Lancet 1994;344:1129-33.

[5] Franks P, Clancy C, Nutting P. Gatekeeping revisited-protecting patients from overtreatment. New Engl J Med 1992;327:424-9.

[6] Blendon RJ, Leitman R, Morrison I, Donelan K. Satisfaction with health systems in ten nations. Health Affairs 1990;185-192.

[7] Calnan M, Katsouyiannopoulos V, Ovcharov VK, Prokhorskas R, Ramic H, Williams S. Major determinants of consumer satisfaction with primary care in different health systems. Fam Pract 1995; 11:468-78.

[8] OECD. OECD Health Systems. Facts and trends. 1960-1991. Paris: OECD, 1993.

[9] Starfield B. Primary care and health. A cross-national comparison. J Am Med Assoc 1991;266:2268-71.

[10] Wensing M, Jung HP, Mainz J, Olesen F, Grol R. Which aspects of general practice care are important for patients? A systematic literature review. Soc Sci Med 1998; in press.

[11] Boerma WGW. Huisbezoek in het buitenland. [Home visits abroad]. Huisarts en Wetenschap 1994;37:546-51.

[12] Olesen F, Jolleys JV. Out of hours service: the Danish solution examined. Br Med J 1994;309:16246.

[13] Van der Voort JPM, Grundmeijer HGLM, Hendrick KMA. NHG-NIPO-enquête 'Huisarts en zinvol handelen' [NHG-NIPO Survey 'The general practitioner and rational treatment']. Huisarts en Wetenschap 1995;38:351-4.

[14] Freeman G, Hjortdahl P. What future for continuity of care in general practice. $\mathrm{Br} \mathrm{Med} \mathrm{J}$ 1997;314:1870-3. 